\title{
The Study of Circular Dichroic Difference Spectra Applied to Polynucleotides and Ribonucleic Acids
}

\author{
Kimitsuna Watanabe, ${ }^{*}$ Takeshi Seno, ${ }^{* *}$ Susumu Nishimura, ${ }^{* *}$ \\ Tairo Oshima, ${ }^{*}$ and Kazutomo IMAHORI \\ The Department of Agricultural Chemistry, Faculty of \\ Agriculture, The University of Tokyo, Bunkyo-ku \\ Tokyo, Japan.
}

(Received September 8, 1972)

\begin{abstract}
The CD difference spectrum was applied to the elucidation of the conformational change in RNA as well as the estimation of its base pair content. First, it was revealed that the RDV RNA recooled form was composed of the fully reconstructed $\mathrm{G}-\mathrm{C}$ pairs and partially destroyed $\mathrm{A}-\mathrm{U}$ pairs, being in good agreement with the result of RNase treatment. Second, the CD difference spectrum of unfractionated $t$ RNA from an extreme thermophile was quite similar to that of $t \mathrm{RNA}_{\mathrm{f}}^{\text {met }}$ from $E$. coli and random copolymer poly $(\mathrm{G}, \mathrm{C})$, showing that the thermophile $t$ RNA is rich in G-C pairs and is consistent with the result of $T_{\mathrm{m}}$ measurement. The limitedly hydrolyzed fragments of $t \mathrm{RNA}_{\mathrm{f}}^{\text {met }}$ by $\mathrm{RNase} \mathrm{T}_{1}$ and their equimolar complexes were also studied. The $\mathrm{CD}$ and $\mathrm{CD}$ difference spectra of 3'-three-quarter molecules (fragment $\mathrm{L}, \mathrm{M}_{3}, \mathrm{M}_{2}$ ) were almost identical but those of their equimolar complexes with $5^{\prime}$-quarter molecule (fragment $\mathrm{N}$ ) were different from each other. Especially $\mathrm{N}+\mathrm{M}_{2}$ revealed a quite different $C D$ pattern from the rest. By combining the work of electrophoresis it was deduced that some false complexes were formed in $\mathrm{N}+\mathrm{M}_{2}$ due to incompleteness of base pairs in the diHU arm.

KEY WORDS Circular Dichroism / CD Difference Spectrum / G-C Pair Content / RDV RNA Recooled form / RNase Treatment / $t \mathrm{RNA}_{\mathrm{f}}^{\mathrm{met}}$ / Thermophile $t \mathrm{RNA} /$ Poly $(\mathrm{G}, \mathrm{C})$ / $t \mathrm{RNA}$ Fragments / Polyacrylamide Gel Electrophoresis /
\end{abstract}

The study on the circular dichroism (CD) of the synthetic polynucleotides which have been selected as model polymers of natural nucleic acids revealed that the patterns of $C D$ are influenced by the species of bases involved, their spatial geometries and the presence or absence of pairing of bases. The $\mathrm{CD}$ patterns are usually characterized by the location of positive and/or negative peaks as well as by their magnitudes which are expressed by a molecular ellipticity coefficient $[\Theta]$ calculated on a molar nucleotide basis.

In a previous paper ${ }^{1}$ two of us reported the CD spectral results of both single and double stranded homo- and copolynucleotides as well as natural double stranded RNA and $E$. coli

* Present address: Mitsubishi-Kasei Institute of Life Sciences, Minamiooya, Machida, Tokyo, Japan.

** Biology Division, National Cancer Center Research Institute, Tsukiji, Chuo-ku, Tokyo, Japan. $t$ RNAs. By reviewing these results it became evident that both the location and magnitude of CD peaks change very sensitively in accordance to the conformation as well as the base composition of the paired regions. However, it is well known that spectral changes are more easily studied by difference spectrum. Thus, it has been suggested that difference CD spectrum would be a better tool to investigate the conformational change or changes in the composition of pairing of bases. Several others ${ }^{2-4}$ have already reported results using $\mathrm{CD}$ difference spectra. In order to estimate the pairing of bases, they used the difference between the organized helical form with base pairs and its single stranded form. However, this method cannot be applied to the estimation of base pairing content or the conformational change in naturally occuring RNA, since it is not possible to obtain perfectly single stranded natural RNA, with base stacking but. 
without base pairing. From this point of view, we tried to use the difference between the native form of RNA and its heat-denatured form. The difference can be interpreted to be the sum of both effects, base-pairing and stacking.

This difference CD spectrum can be used in different ways. If the RNA molecule contains both disorganized and organized conformations, the CD difference spectrum between native and denatured RNA will furnish information about the structure of the organized conformational region. If the conformation of RNA is perturbed by some agent, the $\mathrm{CD}$ difference spectrum between the presence and absence of such a perturbant will provide a useful way to detect and interpret such slight conformational changes.

It has been shown by Fresco, et al. ${ }^{5}$ that the UV difference spectrum is also a good method of carrying out such an investigation. However, since the $C D$ spectrum has been proved to be more sensitive to the conformation of RNA than the UV absorption, ${ }^{6,7}$ we hoped that the $\mathrm{CD}$ difference spectrum would give more detailed information about the conformation of RNA than the UV difference spectrum. In this communication we will report the results of the CD difference spectra applied to elucidating the structures of several RNA species.

\section{EXPERIMENTAL}

\section{Materials}

Poly(adenilic acid) (poly A), polyuridylic acid (poly U), poly(cytidylic acid) (poly C), poly(guanilic acid) (poly $\mathbf{G}$ ) and random copolymer of guanylic acid and cytidilic acid (poly $(G, C)(C: G=1.2: 1)$ were purchased from Miles Laboratories, Inc., Elkhart, Indiana, U.S.A.

The alternating copolymer of adenylic acid and uridylic acid (poly (A-U)) was synthesized in our laboratory using RNA polymerase and poly dAT (alternating copolymer of deoxyadenylic acid and deoxythymidilic acid) as the template. The double helical complex of poly $A$ and poly $\mathrm{U}$ (poly $(\mathrm{A} \cdot \mathrm{U})$ ) was prepared by mixing poly $A$ and poly $U$ in equimolar amounts, followed by keeping overnight at $4^{\circ} \mathrm{C}$, then dializing against a proper solvent. The double helical complex of poly $G$ and poly $C$ (poly $(G \cdot C)$ ) was prepared according to G. J. Thomas, Jr. ${ }^{8}$
Rice dwarf virus (RDV) RNA and cytoplasmic polyhedrosis virus (CPV) RNA were the gifts of Dr. K. Miura, National Institute of Genetics, Mishima. All fractionated $t$ RNAs of $E$. coli and the limited digested fragments of $t \mathrm{RNA}_{\mathrm{f}}^{\text {met }}$ were prepared by some of the present authors (S. N., T.S., and K.W.) and the procedures have been reported elsewhere. ${ }^{9,10}$

An extreme thermophile, Flavobacterium thermophilum HB $8 t \mathrm{RNA}^{11}$ was purified according to the method in the literature. ${ }^{12}$

The CD spectral data of the alternate copolymer of guanylic acid and cytidylic acid (poly $(G-C)$ ) were kindly supplied by Dr. D. Gray and Prof. J. S. Krakow, California University.

Ribonuclease $T_{1}$ (RNase $T_{1}$ (E. C. 2. 7. 7. 26)) and pancreatic ribonuclease (RNase $1 \mathrm{~A}$ (E.C. 2. 7. 7. 16)) were obtained from Sankyo Co., Ltd. (Tokyo, Japan) and Wothington Biochemical Corp. (Freefold, New Jersey), respectively.

\section{Methods}

CD spectra were all obtained on a JASCO ORD/UV-5 spectropolarimeter with $C D$ attachment. The temperature was controlled by circulating water or propyleneglycol of constant temperature from a Haake model FE or Taiyo Coolnit CL-20 thermostatt and monitored by Takara Thermistor- type SPD-1D. The CD measurements were mostly carried at $25^{\circ} \mathrm{C}$ unless otherwise indicated. The hyperchromicity of $t \mathrm{RNA}$ on heating and the absorption increase in RNase treatment were obtained on Gilford spectrophotometer model 240.

Poly(acrylamide) gel was prepared according to the procedure of Loening. ${ }^{13}$ The gel was composed of $15-\%$ (final) acrylamide, 1-\% BIS $(N$, $N^{\prime}$-methylenebisacrylamide), $0.67-\%$ ammonium persulphate, $1 / 300 \mathrm{vol}$ of TEMED $\left(N, N, N, N^{\prime}\right.$ tetramethylenediamine) and the buffer mentioned below. The buffer fill in both the gel and the electrode vessels contained (final concentrations) 0.04- $M$ Tris- $\mathrm{HCl}, \mathrm{pH} 7.3,10-\mathrm{mM} \mathrm{MgAc}_{2}$ and $0.1-\%$ sodium dodecylsulphate (SDS). Electrophoresis was carried out at room temperature at $8 \mathrm{~mA} /$ tube for around $2.5 \mathrm{hr}$. Each sample contained $0.2-\mathrm{OD}_{260}$ units of the fragment, $0.008-\%$ bromophenol blue (BPB) as a marker and 5-\% sucrose. After the run, the gels were gently taken out of the tubes with a long needle, then 
transfered into parallelsided quartz containers and directly scanned at $260 \mathrm{~nm}$ by using a Gilford model 2410 linear gel scanner.

The concentration of base necessary for the determination of molar extinction coefficients $\varepsilon$ and molecular ellipticity coefficient $[\theta]$ was obtained by measuring phosphorus content according to the Ames and Dubins' procedure. ${ }^{14}$

All CD difference spectra were obtained graphically by subtracting the ellipticity coefficient of one form of the polynucleotides from that of another form, over all wavelengths in the absorption band. Consequently, the error of ellipticity coefficient difference $(\Delta[\theta])$ was estimated as within \pm 500 taking into account the conditions employed.

\section{RESULTS}

The Relationship between the Fraction of $G-C$ Content and the Location of the Peak

Before determining the CD difference spectrum it would be useful to examine how the location of $\mathrm{CD}$ peaks will vary depending on the fraction of $\mathrm{G}-\mathrm{C}$ content. This can be realized by measuring the CD spectra of all purified $E$. coli $t$ RNAs available. The results are shown in Figure 1.

The location of the main peak at around $260 \mathrm{~nm}$ can be determined as 267-, 266-, 264-and $263-\mathrm{nm}$ for $t \mathrm{RNA}_{\mathrm{f}}^{\mathrm{met}}, t \mathrm{RNA}_{1}^{\mathrm{va} 1}, t \mathrm{RNA}_{2}^{\mathrm{tgr}}$ and $t \mathrm{RNA}_{2}^{\mathrm{met}}$, respectively. The nucleotide sequences of these $t$ RNAs have been determined and, if we assume the clover-leaf model, the ratio of the number of $\mathrm{G}-\mathrm{C}$ pairs over the total number of base pairs can be counted as $17 / 20^{15}, 15 / 21^{16}$, $17 / 24^{17}$, and $13 / 20^{18}$, respectively for these $t$ RNAs in the order shown above. The fraction of $\mathrm{G}-\mathrm{C}$ content assumed for the four individual $t$ RNAs from their clover-leaf models can be supported by the fact that the melting temperature $\left(T_{\mathrm{m}}\right)$ of these $t$ RNAs decreased in the same order as above. ${ }^{9,19}$

These results clearly indicated that there should be some relationship between the peak location and the fraction of $\mathrm{G}-\mathrm{C}$ content. In fact, by combining the $\mathrm{CD}$ and base composition data of $\mathrm{CPV}^{20}$ and $\mathrm{RDV}^{21}$ RNA which have been reported in our previous paper, ${ }^{1}$ the peak location can be plotted as a linear function of the fraction of $\mathrm{G}-\mathrm{C}$ content, as shown in Figure 2.

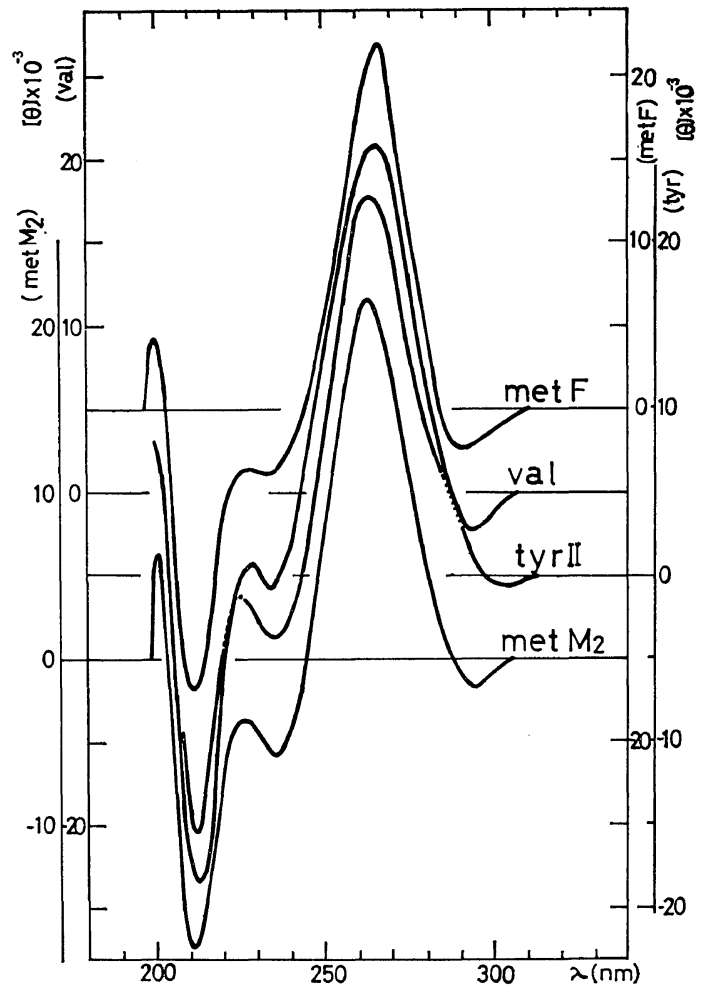

Figure 1. CD spectra of $E$. coli $t$ RNAs specific for methionine ( $F$ and $\mathrm{M}_{2}$ ) valine and tyrosine 2:

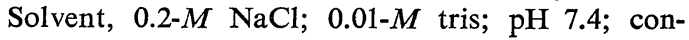
centrations, approx. $10^{-3} M$ nucleotide residues; path length, $1 \mathrm{~mm}$. All CD measurements described below were carried out at the same conditions as this unless otherwise indicated.

The data of the synthetic double stranded polynucleotides of our previous report are shown as well. Although three or four samples deviate from the straight line to some extent, they still at least qualitatively, satisfy the relationship between $\mathrm{G}-\mathrm{C}$ content and the peak location.

\section{Difference Spectrum of the Synthetic Polynucle- otides}

In the treatment of the CD spectrum of $t$ RNA we took only the base paired region into account but neglect the bases in the loop region. This treatment might be too drastic since the bases in the loop region have some contribution to the CD spectrum and there exists a good possibility that such contributions would influence the peak location of the CD spectrum of $t$ RNA. However, if we use a $C D$ difference spectrum, which means 


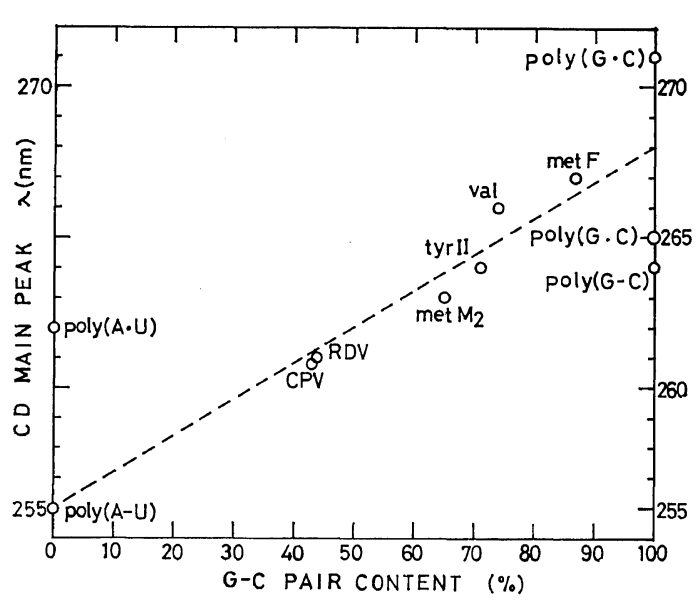

Figure 2. A relationship between the $\mathrm{G}-\mathrm{C}$ pair content and the wave length of $C D$ main peak of various RNAs, the nucleotide compositions of which have been determined. As for $t$ RNA, only the base paired regions or stems under the clover-leaf model were taken into account in calculating the G-C pair content.

the CD spectral difference between the native and denatured forms, we could neglect the contribution of the loop region so far as this region has disordered conformation or the peak position of the CD spectrum does not shift by an unstacking of bases in this region. Before applying CD differences spectrum to $t$ RNA it is necessary to study the difference spectra of model polymers, since the CD difference spectrum of $t$ RNA corresponds to the $\mathrm{CD}$ difference spectrum of base paired region preferentially. Figure 3 shows the CD difference spectra of poly $(A \cdot U)$, poly $(A-U)$, poly $(\mathrm{G} \cdot \mathrm{C})$ and poly $(\mathrm{G}-\mathrm{C})$.

The difference was obtained by point to point subtraction of the molecular ellipticity coefficient $[\theta]$ of the denatured form from that of the native form at $25^{\circ} \mathrm{C}$ over all wavelengths from 210 to $330 \mathrm{~nm}$. The CD spectra of denatured poly (A.U) and poly $(\mathrm{A}-\mathrm{U})$ were obtained by measuring the spectra at $95^{\circ} \mathrm{C}$. However, the $\mathrm{CD}$ spectra of denatured poly $(\mathrm{G} \cdot \mathrm{C})$ and poly $(\mathrm{G}-\mathrm{C})$ were assumed to be equal to the spectra of the mixture of poly $\mathrm{G}$ and dinucleotide $\mathrm{CpC}$ for the former and that of dinucleotide $\mathrm{GpC}$ and $\mathrm{CpG}$ for the latter at higher temperature since it is difficult to denature such double stranded polymers below $100^{\circ} \mathrm{C}$. Each difference spectrum shown in

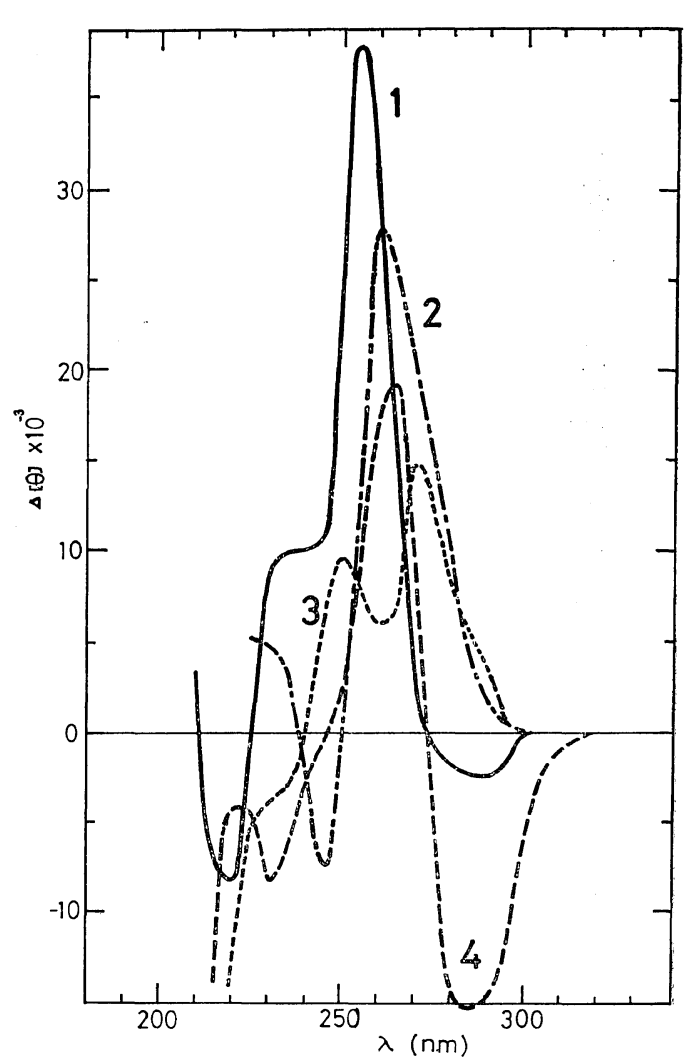

Figure 3. CD difference spectra of four double stranded polynucleotides. The difference spectra were obtained by subtracting the spectra of the denatured from from that of the native form. In the case of poly $(G \cdot C)$ and poly $(G-C)$ the $C D$ spectra of the denatured forms were assumed to be equal to the average of the CD spectra of their single stranded components in their denatured forms.

Curve 1: the difference spectrum of poly $(A-U)$. The spectra of the native and denatured forms were obtained at $30^{\circ} \mathrm{C}$ and $95^{\circ} \mathrm{C}$, respectively, in $0.15-M K F$ solution, $\mathrm{pH}$ 7.5. Curve 2: the difference spectrum of poly (A.U). The spectra of the native and denatured forms were obtained at $30^{\circ} \mathrm{C}$ and $95^{\circ} \mathrm{C}$, respectively; in buffer solution containing 5-mM NaCl, 0.01- $M$ tris; 3-m $M$ EDTA, pH 7.4. Curve 3: the difference spectrum of poly (G.C). The $\mathrm{CD}$ spectrum of the native form was obtained at $30^{\circ} \mathrm{C}$ in a solution containing $0.03-M \mathrm{NaCl}$; 2 $\mathrm{m} M$ EDTA; $\mathrm{pH}$ 7.3. The $\mathrm{CD}$ spectrum of the denatured form was obtained by averaging those of poly $\mathrm{G}$ in $0.1 \mathrm{M}$ tris buffer solution, $\mathrm{pH} 7.5$ at $90^{\circ} \mathrm{C}$ and $\mathrm{CpC}$ in $10-\mathrm{m} M$ tris buffer, $\mathrm{pH} 7.4$ at $90^{\circ} \mathrm{C}$. Curve 4: the difference spectrum of poly $(G-C)$. The CD spectrum of the native form in $1-\mathrm{m} M$ sodium phosphate, $\mathrm{pH} 7.8$ at $20^{\circ} \mathrm{C}$ was obtained by Gray and Krakow and supplied to us. The CD spectrum of the denatured form was obtained by averaging those of $\mathrm{GpC}$ and $\mathrm{CpG}$, both being in $10-\mathrm{m} M$ tris buffer solution, $\mathrm{pH} 7.4$ at $90^{\circ} \mathrm{C}$. 
Figure 3 is similar to the corresponding $C D$ spectrum reported previously, ${ }^{1}$ although slight differences both in the amplitude as well as in peak location could be observed between them.

The CD difference spectra of single stranded homopolynucleotides, poly $\mathrm{A}$, poly $\mathrm{C}$, poly $\mathrm{G}$ and poly $U$ are shown in Figure 4 .



Figure 4. $C D$ difference spectrum between the native and denatured forms of four single stranded homopolynucleotides. The temperatures for obtaining the native and denatured forms are indicated in parenthesis in each case.

Curve 1: the difference curve of poly $\mathrm{C}$ in $0.1-$ $M \mathrm{NaCl}, 0.1-M$ tris, $\mathrm{pH} 7.4\left(27^{\circ} \mathrm{C}, 95^{\circ} \mathrm{C}\right)$. Curve 2: the difference curve of poly $\mathrm{A}$ in $0.1-M \mathrm{NaCl}$, $0.1-M$ tris, $\mathrm{pH} 7.4\left(27^{\circ} \mathrm{C}, 85^{\circ} \mathrm{C}\right)$. Curve 3: the difference curve of poly $\mathrm{G}$ in $0.1-M$ tris, $\mathrm{pH} 7.5$ $\left(25^{\circ} \mathrm{C}, 95^{\circ} \mathrm{C}\right)$. Curve 4: the difference curve of poly $\mathrm{U}$ in $0.15 \mathrm{MKF}$, pH $7.5\left(25^{\circ} \mathrm{C}, 95^{\circ} \mathrm{C}\right)$.

It is noteworthy that the location of the main peak in the difference spectrum of single stranded polynucleotides is completely the same as that of the corresponding CD peak. This is a characteristic for single stranded polynucleotides. As pointed out previously, ${ }^{1}$ double stranded polynucleotides exhibit a considerable red shift of the $\mathrm{CD}$ main band as the temperatures are elevated, while single stranded homopolynucleotides do not shift appreciably. ${ }^{22,23}$ In the case of dinucleotide phosphates, Brahms, et al., have reported that there was no spectral shift of the maximum position of $\mathrm{CD}$ bands at all temperatures used (from about $-20^{\circ} \mathrm{C}$ to $+80^{\circ} \mathrm{C}$ ).$^{24,25}$ From all these results, it may well be concluded that single stranded poly- or oligonucleotides do not exhibit any red shift of the location of their main CD peaks upon heat denaturation. In any case, these results, shown in Figure 4, would be useful for the interpretation of the CD difference spectrum of RNA, which contains single stranded region with strong stacking.

Conformation of the Recooled Form of RDV RNA

When double stranded RDV RNA was denatured by heating at $95^{\circ} \mathrm{C}$ and then cooled slowly to the room temperature the $\mathrm{CD}$ pattern did not recover its original shape, as shown in Figure 5.



Figure 5. CD spectra of RDV RNA in 0.01-SSC solution, $\mathrm{pH} 7.0 \mathrm{P}-$ (Curve 1 ), at $30^{\circ} \mathrm{C}$, (Curve 2), at $90^{\circ} \mathrm{C}, \ldots-\cdot-($ Curve 3 ), the recooled form of RDV RNA (heated to $90^{\circ} \mathrm{C}$ and then cooled to $30^{\circ} \mathrm{C}$ slowly) at $30^{\circ} \mathrm{C}$. 


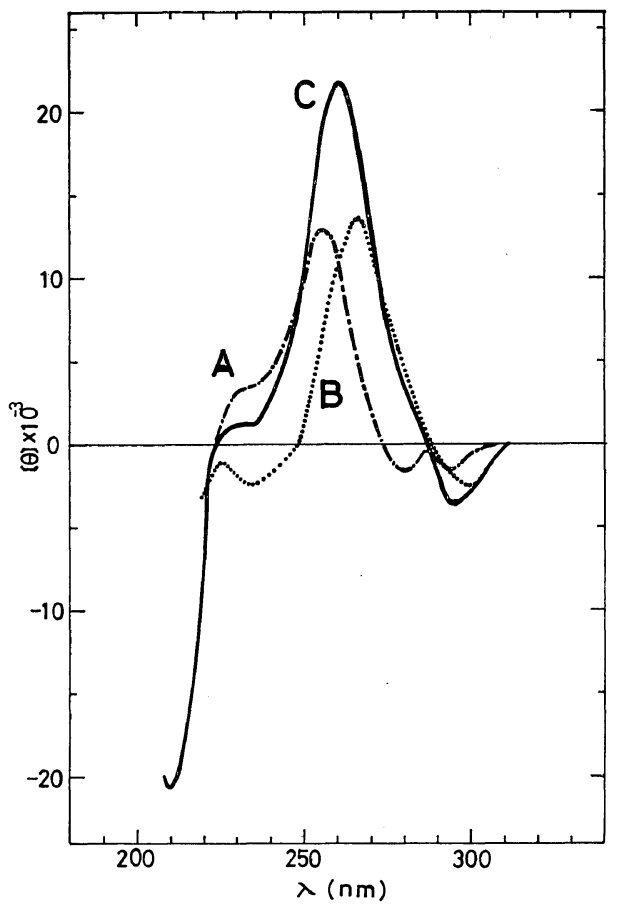

Figure 6. CD difference spectra of RDV RNA obtained by graphical subtraction. -.-.-- (Curve A), ---- (Curve B), - (Curve C) are the differences between curves 1 and 3, 3 and 2, 1 and 2 of Figure 5 respectively.
By comparing the $\mathrm{CD}$ spectrum of the recooled form with that of the native one it is evident that for the recooled form the positive peak at around $260 \mathrm{~nm}$ is smaller and red-shifted from the native form. It can be suggested from Figure 2 that the recooled form has a higher fraction of $\mathrm{G}-\mathrm{C}$ pair content than the native one. Taking the smaller amplitude of the CD peak into account it can be suggested that in the recooling process $\mathrm{G}-\mathrm{C}$ pairs were fully reconstructed but $\mathrm{A}-\mathrm{U}$ pairs were restored only partially leaving mismatched $\mathrm{A}$ and $\mathrm{U}$ as loops. This assumption can be examined by difference spectrum. The results are shown in Figure 6.

In the figure, curves $\mathrm{A}, \mathrm{B}$ and $\mathrm{C}$ represent the difference spectra corresponding to native minus recooled, recooled minus denatured and native minus denatured forms, respectively. As can be expected from the above assumption curve $\mathrm{A}$ is quite similar both in peak location $(255 \mathrm{~nm})$ as well as in the shape to the difference spectrum of poly $(\mathrm{A}-\mathrm{U})$. On the other hand curve $B$ is much like the difference spectrum of poly $(G, C)$, both in shape and peak location. These similarities are shown vividly in Figure 7.

The fraction of $\mathrm{A}-\mathrm{U}$ pairs in the recooled form can be estimated from the results above using a simplified treatment which has been reported previously. ${ }^{1}$ If we assume that the

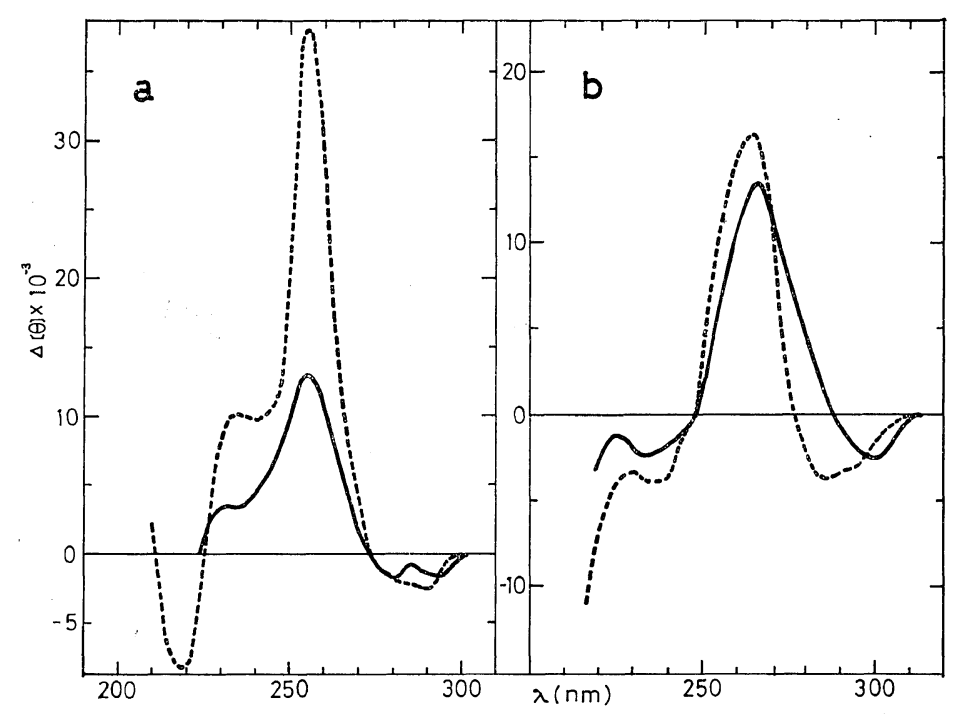

Figure 7. (a) The comparison of curve A of Figure 6 with curve 1 of Figure

3. (b) The comparison of curve B of Figure 6 with curves 3 of Figure 9. 
additivity rule can be applied and that unpaired bases are in a disorganized conformation, the molecular ellipticity of native, denatured and recooled forms can be given as following.

$$
\begin{aligned}
& {[\theta]^{\mathrm{N}}=X_{\mathrm{AU}}[\theta]_{\mathrm{AU}}^{\mathrm{N}}+X_{\mathrm{GC}}[\theta]_{\mathrm{GC}}^{\mathrm{N}} } \\
& {[\theta]^{\mathrm{D}}=X_{\mathrm{AU}}[\theta]_{\mathrm{AU}}^{\mathrm{D}}+X_{\mathrm{GC}}[\theta]_{\mathrm{GC}}^{\mathrm{D}} } \\
{[\theta]^{\mathrm{R}}=} & \left(X_{\mathrm{AU}}-\Delta X_{\mathrm{AU}}\right)[\theta]_{\mathrm{AU}}^{\mathrm{N}} \\
& +\Delta X_{\mathrm{AU}}[\theta]_{\mathrm{AU}}^{\mathrm{D}}+X_{\mathrm{GC}}[\theta]_{\mathrm{GC}}^{\mathrm{N}}
\end{aligned}
$$

Here, $X_{\mathrm{AU}}$ and $X_{\mathrm{GC}}$ represent the fraction of $\mathrm{A}-\mathrm{U}$ pairs and $\mathrm{G}-\mathrm{C}$ pairs contained in the native form and $\Delta X_{\mathrm{AU}}$ means the fraction of $\mathrm{A}$ or $U$, which is not paired in the recooled form. The molecular ellipticity coefficients, $[\theta]_{\mathrm{AU}}^{\mathrm{N}},[\theta]_{\mathrm{AU}}^{\mathrm{D}}$, $[\theta]_{\mathrm{GC}}^{\mathrm{N}}$ and $[\theta]_{\mathrm{GC}}^{\mathrm{D}}$ correspond to those of native poly $(\mathrm{A}-\mathrm{U})$, denatured poly $(\mathrm{A}-\mathrm{U})$, native poly $(\mathrm{G}-\mathrm{C})$ and denatured poly $(\mathrm{G}-\mathrm{C})$, respectively.

From the above three equations, the difference CD spectra between the native and recooled forms as well as between the recooled and denatured forms can be calculated as following:

$$
\begin{aligned}
& {[\theta]^{\mathrm{N}}-[\theta]^{\mathrm{R}}=\Delta X_{\mathrm{AU}}\left([\theta]_{\mathrm{AU}}^{\mathrm{N}}-[\theta]_{\mathrm{AU}}^{\mathrm{D}}\right) } \\
& {[\theta]^{\mathrm{R}}-[\theta]^{\mathrm{D}}=}\left(X_{\mathrm{AU}}-\Delta X_{\mathrm{AU}}\right)\left([\theta]_{\mathrm{AU}}^{\mathrm{N}}-[\theta]_{\mathrm{AU}}^{\mathrm{D}}\right) \\
&+X_{\mathrm{GC}}\left([\theta]_{\mathrm{GC}}^{\mathrm{N}}-[\theta]_{\mathrm{GC}}^{\mathrm{D}}\right)
\end{aligned}
$$

It has been reported by Miura, et al.,$^{21}$ that $X_{\mathrm{AU}}=0.56$ and $X_{\mathrm{GC}}=0.44$ for RDV RNA. The values of $[\theta]_{A U}^{N}-[\theta]_{A U}^{D}$ and $[\theta]_{G C}^{N}-[\theta]_{G C}^{D}$ can be obtained from Figure 3; the former value at $255 \mathrm{~nm}$ is $3.8 \times 10^{4}$ and the latter value is $1.9 \times$ $10^{4}$ at $266 \mathrm{~nm}$. From curve A of Figure 6 the value of $\left([\theta]^{\mathrm{N}}-[\theta]^{\mathrm{R}}\right)$ can be estimated to be $1.3 \times 10^{4}$. Thus, the value of $\Delta X_{\mathrm{AU}}$ can be calculated from eq 4 to be 0.34 . The validity of this value can be tested by eq 5 , which gives the value of $\left([\theta]^{\mathrm{R}}-[\theta]^{\mathrm{D}}\right)$ at $266 \mathrm{~nm}$ to be $1.2 \times$ $10^{4}$. Although this value is somewhat smaller than the peak height of curve B in Figure 6, the agreement is good if we consider the rough assumptions made in eq $1-3$. Rather, the agreement suggests strongly that unpaired bases in the loop region are in a disordered conformation.

The structural model of the recooled form deduced from $C D$ results can be supported by $\mathrm{RNase}$ digestion. If $\mathrm{G}-\mathrm{C}$ pairs are completely restored but $\mathrm{A}-\mathrm{U}$ pairs are only partially restored in the recooled form it can be expected that the phosphodiester bond linked to the $3^{\prime}$ carbon of the unpaired uridine will be easily split by RNase $1 \mathrm{~A}$, while RNase $T_{1}$ would not be able to digest the recooled form since all guauylate residues are in a paired form. ${ }^{20,26,27}$ This expectation is completely fulfilled in Figure 8.

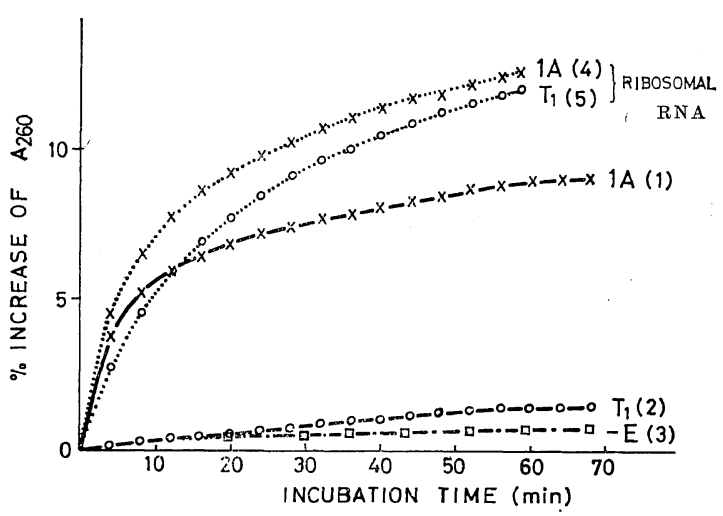

Figure 8. The increase of absorbance at $260 \mathrm{~nm}$ accompanied by the RNase digestion of recooled DVR RNA. The activities were normalized by using heat-denatured E. coli ribosomal RNA as a substrate. It was found that $2.2 \mu \mathrm{g}$ of RNase $\mathbf{T}_{1}$ and $2 \mu \mathrm{g}$ of RNase $1 \mathrm{~A}$ were almost equivalent in their activities, when assayed at $10^{\circ} \mathrm{C}$, as shown by curves 4 and 5 . Then, the susceptibility of recooled RDV RNA was examined using these equivalent amounts of $\mathrm{RNases}$ at $10^{\circ} \mathrm{C}$. These assay mixture contained $1-\mathrm{m} M$ tris- $\mathrm{HCl}$, pH 7.4, 0.05$M \mathrm{NaCl}, 0.01-\mathrm{M} \mathrm{MgCl}_{2}, 0.4-\mathrm{OD}$ unit of recooled RDV RNA and $2.2 \mu \mathrm{g}$ of RNase $\mathrm{T}_{1}$ (curve 2) or $2.0 \mu \mathrm{g}$ of RNase $1 \mathrm{~A}$ (curve 1 ) or without of either RNase (curve 3) in a total volume of $1 \mathrm{ml}$.

The absorbancy at $260 \mathrm{~nm}$ increased remarkably when the recooled form was incubated with RNase 1A but not in the incubation with RNase $T_{1}$, under the condition employed in the present experiment. The amount of two RNases were adjusted so as to digest the heat denatured ribosomal RNA with the same velocity (curves 4 and 5 in the figure). It is not necessary to say that the native form is quite resistant to both RNases under the condition employed here. Thus it has been confirmed that some parts of the $A$ and $U$ residues in the recooled form fail to construct base pairing, however $\mathrm{G}-\mathrm{C}$ pairs are completely restored. 


\section{Difference CD Applied to tRNAs}

The above experiments indicated that a $C D$ difference spectrum is quite useful for studies on the nature of the base paired region of RNA, which contains unpaired bases in the form of a loop. One of the typical exampies of such an RNA would be the $t$ RNA molecule, which based on a clover-leaf model contains three or four loops besides the base paired stem regions. In Figure 9 the native minus denatured difference spectra of $t$ RNA obtained from extremely thermophilic bacterium (Fravobacterium thermophilum HB 8), ${ }^{11} t \mathrm{RNA}_{\mathrm{f}}^{\mathrm{met}}$ of E. coli and random copolymer poly $(G, C)$ are shown. It is evident from the figure that the difference $C D$ spectra are quite similar to each other in the location and amplitude of their peaks.

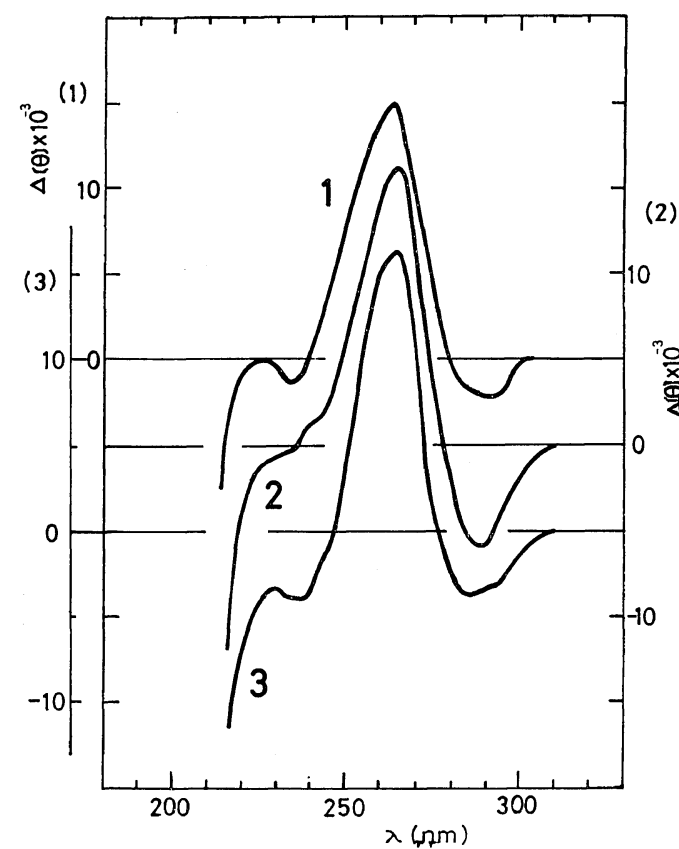

Figure 9. Comparison of the $\mathrm{CD}$ difference spectra of $\mathrm{HB} 8 t \mathrm{RNA}$ (curve 1) $\left(22^{\circ} \mathrm{C}, 91^{\circ} \mathrm{C}\right), t \mathrm{RNA}_{\mathrm{f}}^{\text {met }}$ (curve 2) $\left(31^{\circ} \mathrm{C}, 92^{\circ} \mathrm{C}\right)$ and random copoly $(\mathrm{G}, \mathrm{C})$ (curve 3) $\left(30^{\circ} \mathrm{C}, 92^{\circ} \mathrm{C}\right)$. The differences were obtained between spectra measured at two temperatures as indicated in the parenthesis above.

These results indicate that both $t \mathrm{RNA}_{\mathrm{f}}^{\text {met }}$ and HB $8 t$ RNA have quite high $\mathrm{G}-\mathrm{C}$ content in the base paired stem regions. Further, it is

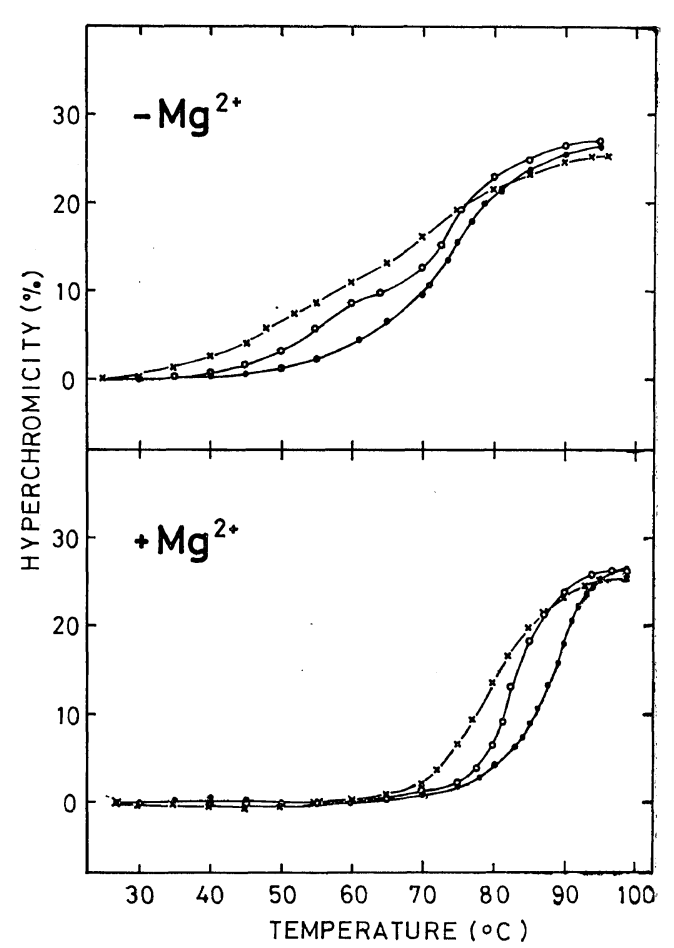

Figure 10. The heating profile of HB $8 t$ RNA (-), $t \mathrm{RNA}_{\mathrm{f}}^{\mathrm{met}}(\mathrm{O}-\mathrm{O}-\mathrm{O})$ and unfractionated $t$ RNA from $E$. coli. $(\times-\times-\times)$. The buffer used contained $0.01-M$ Tris-acetate, $\mathrm{pH} 7.4,0.2-M \mathrm{NaCl}$ and the presence (lower figure) or absence (upper figure) of $10-\mathrm{mM} \mathrm{MgAc}$.

known that the fraction of $\mathrm{G}-\mathrm{C}$ content in the base paired region of $t \mathrm{RNA}_{\mathrm{f}}^{\text {met }}$ is $87 \%,{ }^{15}$ which is the highest value among those reported so far for a $t$ RNA.

It is quite striking that, in spite of the unfractionated sample, $t$ RNA of HB 8 has such a high content of $\mathrm{G}-\mathrm{C}$ pairs. This high $\mathrm{G}-\mathrm{C}$ content can be proved by its high melting temperature. As shown in Figure 10, the melting point of HB $8 t$ RNA in $10-\mathrm{m} M \mathrm{Mg}^{2+}$ can be estimated to be $87^{\circ} \mathrm{C}$, which is $4^{\circ} \mathrm{C}$ and $12^{\circ} \mathrm{C}$ higher than the $T_{\mathrm{m}}$ 's of $t \mathrm{RNA}_{\mathrm{f}}^{\mathrm{met}}$ and the $t \mathrm{RNA}$ mixture of $E$. coli, respectively. The melting temperatures of these $t$ RNA are reproducible and that of the $E$. coli $t$ RNA mixture is in good agreement with previous result. ${ }^{19}$

Probably this high $\mathrm{G}-\mathrm{C}$ content observed for HB $8 t$ RNA is necessary for the bacterium to grow at a high temperature (optimum temper- 


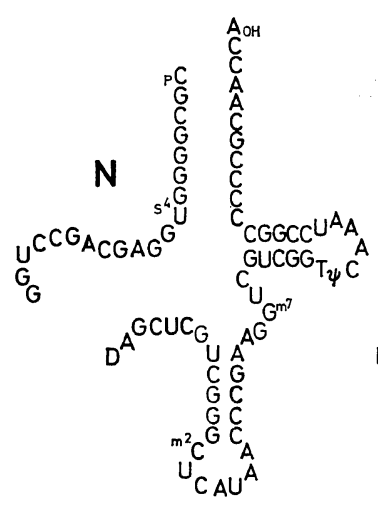

L

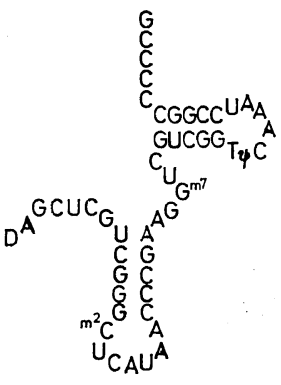

$M_{3}$



$\mathrm{M}_{2}$

Figure 11. The base sequences of the fragments $\mathrm{N}, \mathrm{L}, \mathrm{M}_{3}$, and $\mathrm{M}_{2}$.

ature for growth is about $75^{\circ} \mathrm{C}$ ).

Recently two of the present authors (S. N. and T. S.) have succeeded in obtaining fragments of $t \mathrm{RNA}_{\mathrm{f}}^{\text {met }}$ by limited digestion with RNase $\mathrm{T}_{1}{ }^{10}$ In Figure 11, the base sequences of some of the fragments have been demonstrated.

Fragments $\mathrm{N}$ and $\mathrm{L}$ correspond to the $5^{\prime}$ quarter molecule and $3^{\prime}$-three-quarter molecule of $t \mathrm{RNA}_{\mathrm{f}}^{\mathrm{met}}$, respectively. These fragments result from a cleavage of only one phosphodiester linkage of $t \mathrm{RNA}_{\mathrm{f}}^{\text {met }}$ and the activity can be restored to the same level as that of intact $t$ RNA by complexing them $(\mathrm{N}+\mathrm{L}) .{ }^{10}$ The fragment $\mathrm{M}_{3}$ is missing six nucleotides (CAACCA) from the 3 -terminal of fragment $\mathrm{L}$, while the fragment which lacks three nucleotides (DAG) from the $5^{\prime}$-terminal of $\mathrm{M}_{3}$ is designated as $\mathrm{M}_{2}$. It might be of interest to study the conformations of these fragments and their complexes and compare them to each other as well as with the intact $t$ RNA. It is known the $\mathrm{N}+\mathrm{L}$ complex has the same amino acid accepting activity as that of intact $t$ RNA, ${ }^{10}$ and it would be interesting to see if some specific conformation is required to recover activity in the complex formation. In order to clear this up, the following experiments were undertaken. In Figure 12 the CD spectra of the four fragments are given.

It is evident that the CD spectra of fragments $\mathrm{L}, \mathrm{M}_{2}$ and $\mathrm{M}_{3}$ are almost identical although their base compositions are somewhat different from each other. This finding suggested that the CD spectra of these fragments are mostly due to their intramolecular base paired region and the con-

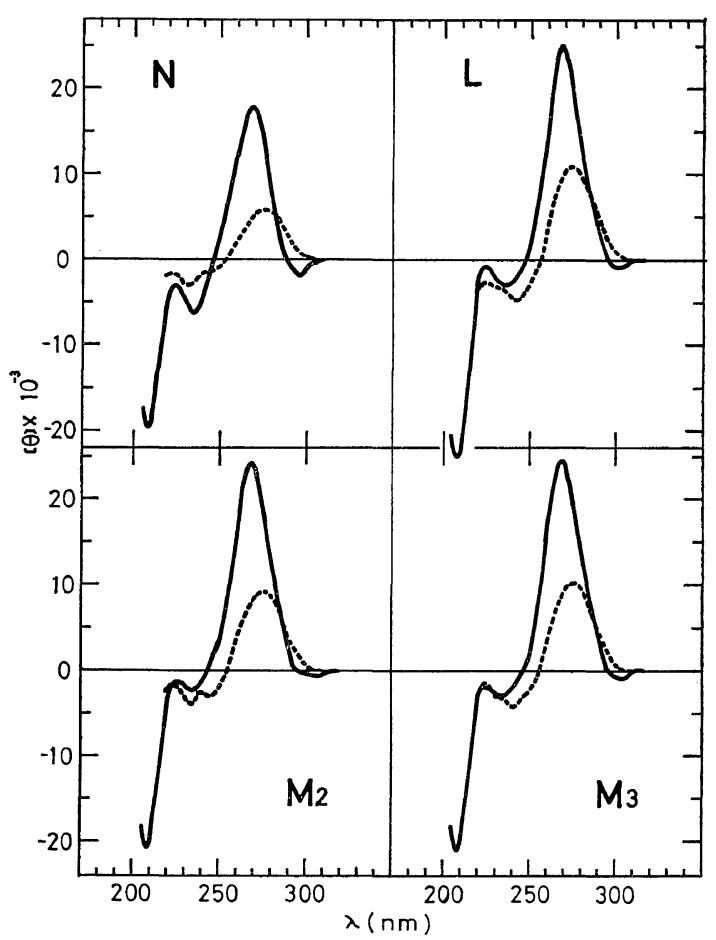

Figure 12. The $C D$ spectra of the fragments $N$, $\mathrm{L}, \mathrm{M}_{3}$, and $\mathrm{M}_{2}$ at the two temperatures solid line, $30^{\circ} \mathrm{C}$ dotted line, $95^{\circ} \mathrm{C}$ ) in the presence of $\mathrm{MgAc}_{2}$.

tribution of the unpaired region would be very small, if any. The existence of the base paired region is supported by the CD difference spectra, which are shown in Figure 13.

Actually, the CD difference spectra are almost identical to each other, especially in the absence 




Figure 13. The CD difference spectra of fragments $\mathrm{N}, \mathrm{L}, \mathrm{M}_{3}$ and $\mathrm{M}_{2}$. The differences were obtained by subtracting the dotted line curve from the solid line curve of Figure 12. The left and right columns correspond to the presence and absence of $\mathrm{MgAc}_{2}$, respectively.

of $\mathrm{Mg}^{2+}$ and are very similar to that of poly $(G, C)$. If we assume that base pairs such as those indicated in Figure 11 really exist in these fragments, it is natural that the resulting $C D$ difference spectra are nearly equal to that of poly $(G, C)$. The existence of such base pairing in these fragments can be supported by IR spectral results, ${ }^{28}$ which seem to give more detailed information about the presence of base pairs.

In Figures 12 and 13 we can see that fragment $\mathrm{N}$ behaves somewhat differently from the rests. Moreover, the presence and absence of $\mathrm{Mg}^{2+}$ have a significant influence on the CD spectra. This can be interpreted by assuming that in the absence of $\mathrm{Mg}^{2+}$, fragment $\mathrm{N}$ is almost in a single stranded conformation and does not contain appreciable amount of base pairing. Accordingly, when the temperature was elevated the

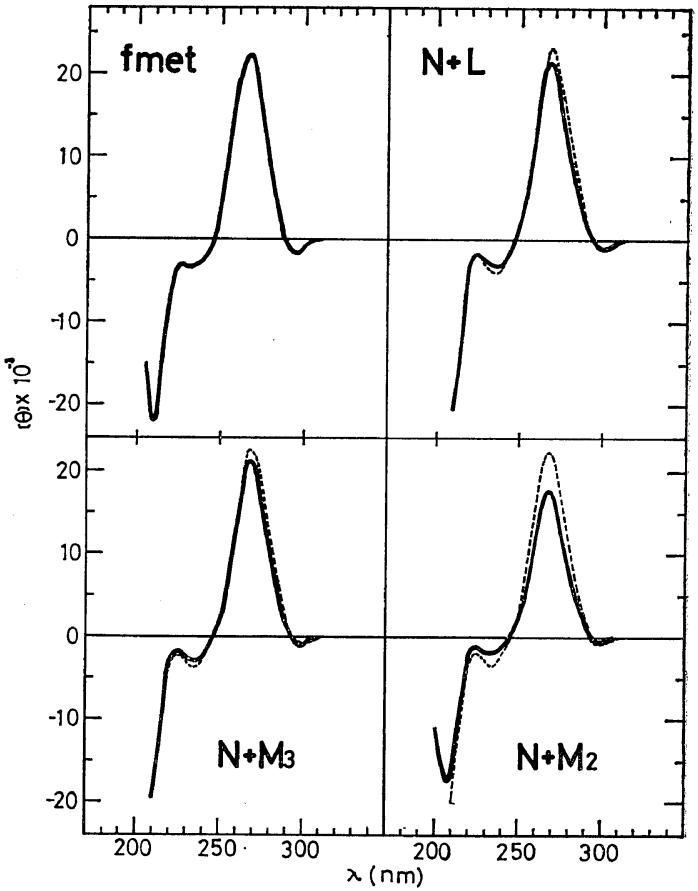

Figure 14. The CD spectra of $t \mathrm{RNA}_{\mathrm{f}}^{\text {met }}$, fragments $\mathrm{N}+\mathrm{L}, \mathrm{N}+\mathrm{M}_{3}$ and $\mathrm{N}+\mathrm{M}_{2}$ in $10-\mathrm{m} M \mathrm{MgAc}_{2}$ (solid line). The graphical average $(1: 1)$ of the spectra of components measured separately are also indicated (dotted line).

CD magnitude decreased but the peak location did not shift much. It has been described above that the denaturation of the single stranded polynucleotide is not accompanied by a peak shift while a noticeable red shift of the CD peak characterizes the double stranded polynucleotides.

While, in the presence of $\mathrm{Mg}^{2+}$ as shown in Figure 12, a considerable red shift was observed on heating. This shift may be appreciated as the formation of some intra or intermolecular base pairs.

As mentioned above, in an equimolar mixture of fragments $N$ and $L(N+L)$ a $1: 1$ complex is formed and this complex has full activity for amino acid acceptance. ${ }^{10}$ It would be interesting to compare the conformation of this complex with that of $t \mathrm{RNA}_{\mathrm{f}}^{\mathrm{met}}$ to see if secondary structure would be restored by complex formation. In addition, we have examined the CD spectra of equimolar mixtures of fragments $\mathrm{N}$ and $\mathrm{M}_{3}$ $\left(N+M_{3}\right)$ and of fragments $N$ and $M_{2}\left(N+M_{2}\right)$. 
The results are shown in Figure 14.

It is evident that the spectra of $\mathrm{N}+\mathrm{L}$ and $\mathrm{N}+\mathrm{M}_{3}$ are almost identical with that of intact $t \mathrm{RNA}$, but are different from the corresponding theoretical curves, which are obtained by the graphical summation of the CD spectra of the components. Probably this slight conformation change accompanying the complex formation would be important in restoring the activity. It is noteworthy that the CD spectrum of $\mathrm{N}+\mathrm{M}_{2}$ is quite different from the rests, with a peak of smaller magnitude. Actually, when we obtain the weighted average of the $C D$ patterns of $N$ and $\mathrm{M}_{2}$ from Figure 12, the resulting pattern is revealed to have a peak with greater magnitude than that obtained for $\mathrm{N}+\mathrm{M}_{2}$. This suggests that there exist some false complexes where the original secondary structure of $\mathrm{M}_{2}$ is destroyed.

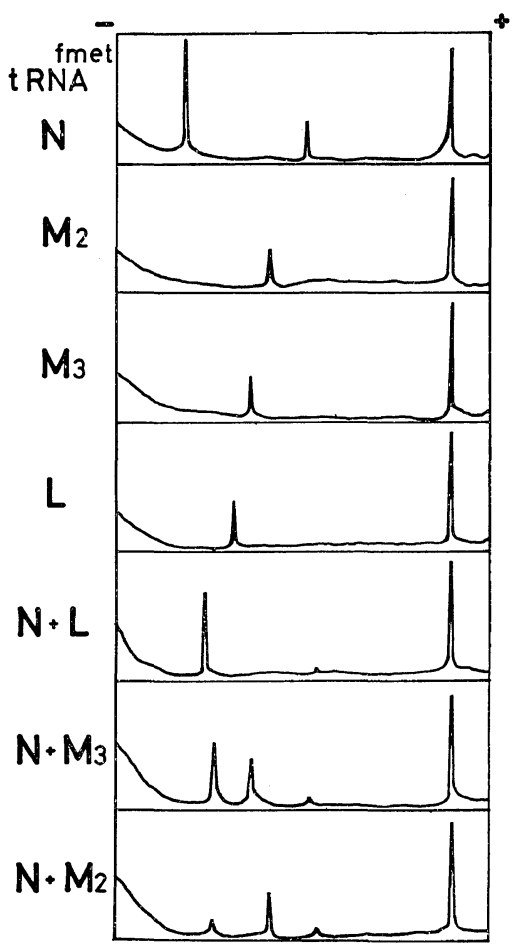

Figure 15. The electrophoretic patterns of $t \mathrm{RNA}_{\mathrm{f}}^{\text {met }}$, fragments $\mathrm{N}, \mathrm{M}_{2}, \mathrm{M}_{3}, \mathrm{~N}+\mathrm{L}, \mathrm{N}+\mathrm{M}_{3}$ and $\mathrm{N}+\mathrm{M}_{2}$. The procedures are described in Methods. The abscissa indicates the distance along each gel with the sharp peaks to the right those of BPB used as a marker. The ordinate indicates the relative absorbance measured at $260 \mathrm{~nm}$.
The results obtained by CD spectra can be further supported by electrophoretical studies. When these equimolar mixtures of $\mathrm{N}+\mathrm{L}, \mathrm{N}+\mathrm{M}_{2}$, and $\mathrm{N}+\mathrm{M}_{3}$ were examined on acrylamide gel electrophoresis, as shown in Figure 15, it became evident that $\mathrm{N}+\mathrm{L}$ was completely reconstituted and more than half of $\mathrm{N}+\mathrm{M}_{3}$ was reconstituted into a $1: 1$ complex. However, in $\mathbf{N}+\mathbf{M}_{2}$ only a slight peak could be observed in the position expected for an $\mathrm{N}+\mathrm{M}_{2}$ complex.

Since SDS was added to the gel to avoid some artifact aggregation, part of the $\mathrm{N}+\mathrm{M}_{2}$ complex could have been destroyed to some extent. However, the peaks corresponding to the fragments of $\mathrm{N}$ and $\mathrm{M}_{2}$ are not sufficient to account for such degradation. As mentioned above, the possibility of such degradation can be excluded from the $C D$ results. However, it was often observed that peaks appeared at the negative side of the right complex peak position and a broad peak observed at the negative extreme is too large to be neglected. These electrophoretic results would suggest some "wrong" complexes were formed in the mixture of $\mathrm{N}$ and $\mathrm{M}_{2}$. In addition, there are also preliminary data supporting this. ${ }^{29}$ When the complex formation of $\mathrm{N}$ and $\mathrm{L}$ was tested based on the amino acid accepting activity in the presence of $M_{3}$ or $M_{2}$, it was observed that the fragment $M_{3}$ was able to inhibit the amino acid accepting activity, but the fragment $M_{2}$ was not. These results suggest that the fragments $\mathrm{N}$ and $\mathrm{M}_{3}$ can also form a complex similar to that of $\mathrm{N}+\mathrm{L}$ but $\mathrm{N}$ and $\mathrm{M}_{2}$ cannot form such a complex. Probably the lack of $5^{\prime}$-terminal nucleotide in $\mathrm{M}_{2}$ not only prevents the reconstitution of the right clover-leaf structure but favors the formation of such false complexes as mentioned above.

\section{DISCUSSION}

The CD spectrum of RNA is influenced by many structural and conformational factors. The conformation of base in each nucleotide, the mode of base stacking, pairing between complementary bases and base compositions in the unstacked, stacked and base paired regions are counted as main factors. If RNA is purely in one conformation, for example in the double stranded conformation, the circular dichroic 
spectrum can be easily assigned. However, most of the natural RNAs have several conformational regions in one molecule. In the case of a clover-leaf model for $t$ RNA we can count base paired stem regions, loop regions, where the bases would be stacking to some extent but not paired, and a single stranded terminal region. It is known that the CD pattern of RNA is sensitive to its conformation. Thus, even if each region has the same base composition, the CD patterns resulting from base paired, loop and single stranded regions should be quite different from each other. If we know the complete three-dimensional structure of such an RNA it would be possible to construct its CD pattern by using the approximation calculation method described elsewhere. ${ }^{1,32}$ However, this does not mean that an RNA structure can be determined by analizing its $C D$ spectrum. The real difficulty in the application of $\mathrm{CD}$ techniques for the structural study of RNA is solving this problem.

In order to overcome this difficulty to some extent, we have tried to study $\mathrm{CD}$ difference spectra of RNA. If we assume that the conformation of the loop and single stranded regions would be nearly the same as that of the heat denatured RNA, we could cancel the CD contribution of such regions by subtracting the $\mathrm{CD}$ spectrum of a heat denatured RNA from that of a native one. Once we could obtain the CD spectrum of the base paired regions exclusively, it became possible estimate the base composition or the size of that region. Even though such assumptions cannot be maintained, the $C D$ difference spectrum would be useful as far as the peak location is concerned. Since the melting point of the single stranded region does not accompany the peak shift, the peak location of the CD difference spectrum is insensitive to the conformation of the loop region. Moreover, in the case of $E$. coli $t \mathrm{RNA}$, the base compositions of the loop regions are very similar to one another. For example, when the base composition of the loop region is compared with that of the base-paired stem region, based on the clover-leaf structure, the variety of the latter is revealed to be much larger than that of the former as shown schematically in Figure 16.

This fact also supports the validity of the $\mathrm{CD}$ difference spectrum of $t \mathrm{RNA}$, because we
BASE COMPOSITION $(\%)$

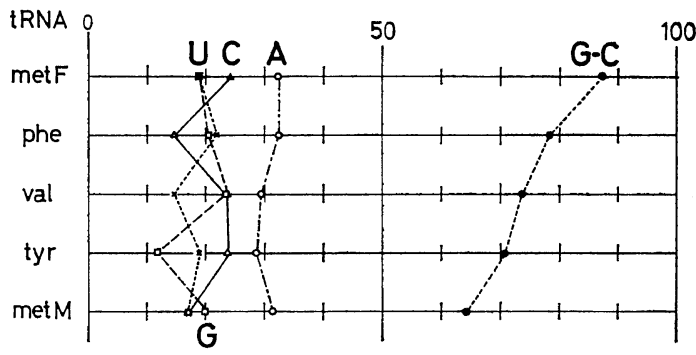

Figure 16. The variety of base composition in the loop and base paired stem regions of $E$. coli $t$ RNA. The base composition of the loop region was calculated as follows:

$\mathrm{N}(\mathrm{A}, \mathrm{C}, \mathrm{G}, \mathrm{U})$, the number of $\mathrm{N}$ residue/the number of total bases in loop region; $A\left(\mathrm{O}^{---} \mathrm{O}\right)$, $\mathrm{U}(\times-\cdots \times), \mathrm{G}(\square--\square), \mathrm{C}(\triangle-\triangle)$. As for the minor bases, each was classified as the most similar bases among the normal bases. For example, both rT (ribothymidine) and $\Psi$ (pseudouridine) were classified as $\mathrm{U}, \mathrm{m}^{7} \mathrm{G}$ (7-methlguanosine) as $\mathrm{G}, \mathrm{m}^{2} \mathrm{C}$ (2-methylcytidine) as $\mathrm{C}$, but DiHU (dihydrouridine) and $4 \mathrm{TU}$ (4-thiouridine) bases were neglected because they do not contribute to $C D$ spectrum around $260 \mathrm{~nm}^{32,33}$ The base composition of the stem region was calculated as follows: $\mathrm{G}-\mathrm{C}$ (---), the number of $\mathrm{G}-\mathrm{C}$ pairs/the total number of base pairs. When $\mathrm{G}-\mathrm{U}$ pair is contained in the stem region, it was assumed that a half of the G-C pair was involved, so the factor $1 / 2$ was added to the numerator described above.

can interpret the loop region common in each species of $t$ RNAs as making almost the same contribution to each CD spectra. This is compensated by the use of CD difference spectrum.

The experiments on the recooled form of RDV RNA indicated the usefulness of CD difference spectrum on one hand and the soundness of the above assumption on the other. It is evident that the CD spectrum of the recooled form is different from those of the native and denatured forms. Because of the red shift and decrease in magnitude of the positive peak, it could be deduced from the $C D$ spectrum that in the recooled form $\mathrm{G}-\mathrm{C}$ pairs were mostly reconstructed but A-U pairs were restored only partly. Furthermore, this conclusion has been proved by the CD difference spectrum. The difference spectrum between the native form and the recooled form is quite in agreement with the difference 
spectrum of poly (A-U) both in shape as well as in peak location (Figure 7). This finding indicates strongly that only $\mathrm{A}-\mathrm{U}$ pairs but not G-C pairs are broken in the recooled form and that unpaired will be in a disorganized loop conformation. If $\mathrm{G}-\mathrm{C}$ pairs are broken or if unpaired bases are stacked strongly it will result in a $C D$ difference spectrum different from that of poly $(\mathrm{A}-\mathrm{U})$. The advantage of $\mathrm{CD}$ difference spectrum seems to be that it enables us to estimate the fraction of unpairing or pairing of bases in the recooled form. These results were further supported by the CD difference spectrum between recooled and denatured forms. This CD difference spectrum can be explained by the model which has been derived from the previous difference spectrum.

Once the validity of the $\mathrm{CD}$ difference spectrum has been proved it is natural to extend its application to other RNAs. The result of the CD difference spectra of $t \mathrm{RNA}_{\mathrm{f}}^{\mathrm{met}}$, the fragments of it, and HB $t$ RNA have revealed the base compositions in base paired region and the existence of such region. It is not necessary to say that we can estimate the fraction of paired bases in the RNA molecule from the magnitude of the CD difference peak.

The present study strongly indicates that the heat stability of the thermophile $t$ RNA (mixture) is due to its high content of $\mathrm{G}-\mathrm{C}$ pairs in the molecule. If we take into consideration that the molecular size of $t$ RNA is similar to that of $E$. coli ${ }^{7}$ and that the thermophile $t$ RNA can be replaced by $E$. coli $t$ RNA in the methionyl$t$ RNA froming reaction catalized by the purified E. coli enzyme ${ }^{30}$ (methionine: sRNA ligase E. C. 6.1.1.10), then it is conceivable that the structures around the sites which interact with amino acid- $t$ RNA ligases, could have been conserved during the evolutionary process of the possible methophile ancestor to the present thermophile. However, most of $\mathrm{A}-\mathrm{U}$ pairs in the ancestor $t$ RNA molecules might have been replaced by $\mathrm{G}-\mathrm{C}$ pairs to make the nucleic acids more heat resistant. More detailed studies on the chemical structure of the thermophile $t$ RNA including CD measurements on the $t$ RNA of a single molecular species, will be of interest in respect to the structure-function relationship of $t$ RNAs and a study on this line is now under way.
The application of CD difference spectrum can be extended to the study of a slight conformational change of RNA. It is well known that a slight conformation change of the enzyme induced by the binding of a substrate, for example can be easily detected by UV difference spectrum. Similarly, CD difference spectrum would provide a useful tool for the detection and interpretation of the slight conformational change of an RNA molecule, brought about by its binding with a protein or other molecule. Such an application of the CD difference spectrum has been undertaken in our laboratory and its usefulness has been proved. The results will be published soon. ${ }^{31}$

Although the information available from the CD difference spectrum is similar to that of the UV difference spectrum, which was extended by Fresco, et al.,$^{5}$ it is hoped that the CD difference spectrum will provide more detailed structural information than the UV difference spectrum, since the $C D$ spectrum itself is much more sensitive to the conformation and base composition of RNA molecule.

Acknowledgment. We thank Dr. K. Miura, National Institute of Genetics, Mishima, Japan for the supply of RDV RNA. Our thanks are due to Laboratories of Kaken Chemicals Ltd. for the supply of $E$. coli paste and isolation of crude $E$. coli $t$ RNA. This work was supported in part by a grant from the Ministry of Education of Japan.

\section{REFERENCES}

1. K. Imahori and K. Watanabe, J. Polym. Sci., Part C, 30, 633 (1970).

2. R. B. Gennis and C. R. Cantor, Biochemistry, 9, 4714 (1970).

3. G. Green and H. R. Mahler, ibid., 10, 2200 (1971).

4. R. H. Reeves, C. R. Cantor, and R. W. Chambers, ibid., 9, 3993 (1970).

5. J. R. Fresco, L. C. Klotz, and E. G. Richards, Cold Spring Harbor Symposia Quant. Biol., 28, 83 (1963).

6. J. Brahms, J. Amer. Chem. Soc., 85, 3298 (1963).

7. I. Tinoco, Jr., ibid., 86, 297 (1964).

8. G. J. Thomas, Jr., Biopolymers, 7, 325 (1969).

9. S. Nishimura, F. Harada, U. Narushima, and T. Seno, Biochim. Biophys. Acta, 142, 133 (1967). 
10. T. Seno, M. Kobayashi, and S. Nishimura, Biochim. Biophys. Acta, 190, 285 (1969).

11. T. Oshima and K. Imahori, J. Gen. Appl. Microbiol., 17, 513 (1971).

12. G. von Ehrenstein and F. Lipmann, Proc. Nat. Acad. Sci. U.S., 47, 941 (1961)

13. U. E. Loening, Biochem. J., 102, 251 (1967).

14. B. N. Ames and D. T. Dubin, J. Biol. Chem., 235, 769 (1960).

15. S. K. Dube, K. A. Marcker, B. F. C. Clark, and S. Cory, Nature, 218, 232 (1968).

16. M. Yaniv and B. G. Burrell, ibid., 222, 278 (1969).

17. H. M. Goodman, J. Abelson, A. Landy, S. Brenner, and J. D. Smith, ibid., 217, 1019 (1968).

18. S. Cory, K. A. Marcker, S. K. Dube, and B. F. C. Clark, ibid., 220, 1039 (1968).

19. T. Seno, M. Kobayashi, and S. Nishimura, Biochim. Biophys. Acta, 174, 71 (1969).

20. K. Miura, I. Fujii, T. Sasaki, M. Fuke, and S. Kawase, J. Virol. 2, 1211 (1968).

21. K. Miura, I. Kimura, and N. Suzuki, Virology, 28, 571 (1966).
22. J. Brahms and W. F. H. M. Mommaerts, J. Mol. Biol., 10, 73 (1964).

23. H. Hashizume and K. Imahori, J. Biochem., 61, 738 (1967).

24. K. E. van Holde, J. Brahms, and A. M. Michelson, J. Mol. Biol., 12, 726 (1965).

25. J. Brahms, J. C. Maurizot, and A. M. Miche1son, ibid., 25, 481 (1967).

26. K. Miura, I. Fujii, T. Sasaki, S. Kawase, and M. Fuke, Abstracts, 7th International Congress of Biochemistry, Tokyo, August, 1967, B-5.

27. M. A. Bilkter, C. Weissmann, and R. C. Warner, J. Mol. Biol., 17, 145 (1966).

28. T. Katsura, K. Morikawa, M. Tsuboi, Y. Kyogoku, T. Seno, and S. Nishimura, Biopolymers, 10, 681 (1971).

29. T. Seno, unpublished data.

30. Y. Takasaki, T. Oshima, and K. Imahori, to be published.

31. K. Watanabe and K. Imahori, in preparation.

32. C. R. Cantor, S. R. Jaskunas, and I. Tinoco, Jr., J. Mol. Biol., 20, 39 (1966).

33. T. Samejima, M. Kita, M. Saneyoshi, and F. Sawada, Biochim. Biophys. Acta, 179, 1 (1969). 